\title{
Weathering in the Ganga Alluvial Plain: Geochemical signatures linking of the Himalayan source and the Bay of Bengal sink
}

\author{
Indra Bir Singh ${ }^{1}$, Sandeep Singh ${ }^{2}$ and Munendra Singh ${ }^{1}$ \\ 1 Centre of Advanced Study in Geology, University of Lucknow, Lucknow 226 007, INDIA \\ 2 Department of Earth Science, Indian Institute of technology, Roorkee 247 667, INDIA
}

The Ganga Alluvial Plain is basically formed by the Himalayanderived sediments and serves as transient zone between the Himalaya (source) and the Bay of Bengal (sink). The plain experiences a strong geochemical weathering leading to fractionation and elemental partitioning under sub-tropical climatic conditions controlled by heavy monsoon rainfall with long periods of drought and high ambient temperatures. It plays an important role in geochemical dynamics of this region as compared to the Himalayan area. The chemical weathering of the Ganga Alluvial Plain sediments is more intense than in the Himalaya. In the Ganga Alluvial Plain, the loss of $\mathrm{Na}, \mathrm{Ca}$ and $\mathrm{Sr}$ during weathering is noticeable. Weathering products of the Ganga Alluvial Plain are the results of incomplete alteration of deposited alluvial sequences under humid sub-tropical climate. Annual physical and chemical denudation rates, based on total suspended matter $(40 \mathrm{mg} / \mathrm{L})$ and total dissolved solid $(260 \mathrm{mg} / \mathrm{L})$, are 9.7 tons/ $\mathrm{km}^{2}$ and 63.1 tons $/ \mathrm{km}^{2}$, respectively. In spite of high lithological, climatological and tectonic variability in the Himalayan region, the denudation rates in the Ganga Alluvial Plain are higher (26 $\%$ in physical erosion rate) and (73\% in chemical erosion rate) than the Ganga River catchment in the Himalaya. The Gomati
River sediments experience incipient to moderate intensity of the Chemical Index of Alteration (CIA) leading to higher CIA values than those of the Himalayan derived rivers.

The Gomati River, an important alluvial tributary of the Ganga River, drains nearly $30,500 \mathrm{~km}^{2}$ area of the Ganga Alluvial Plain. The river recycles the Himalayan derived sediments and transports its weathering products into the Ganga River to be transferred to the Bay of Bengal. The Gomati River water has dissolved $\mathrm{Sr}$ concentrations $375 \mu \mathrm{g} / \mathrm{L}$, which is more than five times higher than the world's average of river water $(70 \mu \mathrm{g} / \mathrm{L})$ and nearly three times higher than the Ganga river water in the Himalaya $(130 \mu \mathrm{g} / \mathrm{L})$. Dissolved Selenium concentration is also reported as high as $1120 \mu \mathrm{g} / \mathrm{L}$.

The Ganga Alluvial Plain is a significant geochemical linkage between the source (the Himalaya) and the sink (the Bay of Bengal). At present, most of the interpretation dealing with the sinks of the Ganga Fluvial System is profoundly linked with the geological processes operating in the Himalayan region alone. The importance of monsoon controlled hydro-geochemical processes operating in the Ganga Alluvial Plain, therefore, should be emphasized in interpretation of elemental mobility, cycling and budgets of the Ganga Fluvial system. 